\title{
PODER Y FIGURAS DE LA RESISTENCIA EN LA NARRATIVA DE LUCÍA GUERRA
}

\section{POWER AND RESISTENCE FIGURES IN THE NARRATIVE OF LUCIA GUERRA}

\author{
Monserrat Polanco Madariaga \\ Pontificia Universidad Católica de Valparaíso \\ monserrat.polanco@pucv.cl
}

\begin{abstract}
Resumen:
La narrativa de la escritora chilena Lucía Guerra se construye en torno a modulaciones del poder que se articulan en torno al mito fundante de la historia de Occidente y sus saberes. Desde esta perspectiva, el presente artículo analiza de qué forma se tensiona la lucha de poderes entre un sujeto en resistencia que desea ser consciente de sí mismo y de la historia, y las inscripciones históricos-patriarcales-positivistas que recaen sobre cuerpo e identidad y cuáles serían, entonces, las fisuras del poder que traza la escritora. Desde este cometido, los postulados de Michel Foucault son fundamentales debido a que establece que la resistencia siempre está presente en el entramado del poder. A través de diferentes técnicas narrativas, tales como instalar la ambigüedad en identidades y realidades, el uso de lo fantástico y lo onírico, se puede advertir en su obra una voz subversiva, a veces, muy explícita, y otras, dejando caer la duda frente a los saberes dominantes.
\end{abstract}

Palabras claves: fisura del poder, resistencia, cuerpo, identidad.

\begin{abstract}
:
The narrative of the chilean Lucía Guerra's narrative is built around modulations of power that are articulated around the founding myth of Western history and its knowledge. From this perspective, this article analyzes how the power struggle between a subject in resistance who wishes to be aware of himself and of history, and the historical-patriarchalpositivist inscriptions that fall on body and identity are stressed and which They would be, then, the fissures of power that the writer traces. From this mission, Michel Foucault's postulates are fundamental because he establishes that resistance is always present in the fabric of power. Through different narrative techniques, such as installing ambiguity in identities and realities, the use of the fantastic, the dreamlike, a subversive voice, sometimes very explicit, and others, can be seen in his work, dropping the doubt in front of the dominant knowledge.
\end{abstract}

Kerwords: power fissure, resistance, body, identity.

Recibido: 30 de septiembre de 2020

Aceptado: 09 de noviembre de 2020 
“AA empellones se hace la historia, compañeras!, exclamó en voz alta [Luego] esbozó una sonrisa diciéndose que la historia no era otra cosa que un cauce disparejo de aguas que nunca cesan de resistir" Muñeca Brava. LUCÍA GUERRA

"Escriba, escriba mucho, me había dicho Aurora, porque ella siempre creyó en el poder de las palabras". Más allá de las máscaras. LUCÍA GUERRA

La narrativa de la escritora chilena Lucía Guerra Cunningham representa una posibilidad real de adentrarse en la problemática de la existencia del poder y cómo los sujetos se resisten a este. Ciertamente, tanto poder como resistencia se construyen de manera narrativa, discursiva y políticamente en su escritura. Sus textos están marcados por una posición política frente a la violencia, la muerte, el desamparo, la discriminación, el desarraigo y la desposesión del sujeto. En el mismo tono, Michel Foucault piensa que: "La literatura, en realidad, sólo existe en la medida en que no dejamos de hablar, en la medida en que no dejamos de poner signos en circulación" (La gran extranjera 112). Por ello, la narrativa de Guerra es relevante, en tanto examina cómo los saberes dominantes a lo largo de la historia han sometido a los sujetos a una idea reguladora que inscribe sobre ellos marcas y signos que los dejan en un estado de precariedad. A través de técnicas narrativas, como el uso de lo fantástico y onírico -que se entrelazan- Lucía Guerra instala la ambigüedad en identidades y 'realidades'. Tzvetan Todorov al definir lo fantástico señala: “[...] lo fantástico se basa esencialmente en una vacilación del lector -de un lector que se identifica con el personaje principal- referida a la naturaleza de un acontecimiento extraño" (114). Esta función se puede advertir en la densidad de su obra a partir de una voz subversiva, a veces muy explícita $\mathrm{y}$, otras, dejando caer la duda frente a los saberes dominantes. Por ello, situar su narrativa en un horizonte conceptual en torno al poder y la resistencia resulta clave, pues tales nociones se entrelazan con su tarea como teórica, dejando claro que la ficción y la teoría literaria pueden ir juntas.

En este sentido, la producción escritural de Guerra cobra relevancia en tanto el poder es un campo discursivo atractivo en tiempos de re-significación de la posición social de minorías que han sido excluidas históricamente, y donde asistimos a la confrontación con la narración lineal de una historia que devino en sometimiento y opresión. De cara a esta situación, abordar las fronteras de la identidad considerando su multiplicidad y los 
esfuerzos de posicionamiento del sujeto como una práctica política portadora de sentido en la enunciación, invita a ensayar y merodear en torno a la trama del poder elaborada en la literatura. Pues, tal como advierte Byung-Chul Han: “[...] el poder está precisamente allí donde no es tematizado. Cuando mayor es el poder más silenciosamente actúa" (27). Del mismo modo, examinar la experiencia del sujeto en sus tensiones con el poder implica adentrarse en la literatura determinando quién escribe y refuta al conocimiento totalizador del poder/saber y sus repercusiones, en especial, en tiempos donde el ser humano se atiene a lo inmediatamente dado.

Situando la problemática en América hispana, Aníbal Quijano en su ensayo "Colonialidad del poder, Eurocentrismo y América Latina", nos aporta una propuesta epistémica sobre la colonialidad del poder para la estructuración de la sociedad. Para este teórico, su constitución como moderna se hizo al amparo de un patrón basado en el eurocentrismo y la diferenciación con sujetos inferiores expresados en estructuras de poder: "Por eso, la nueva perspectiva geográfica de la historia y de la cultura, que allí es elaborada y que se impone como mundialmente hegemónica, implica, por supuesto, una nueva geografía del poder" (792). Es entonces, en la tensión entre igualdad y diferencia desde donde se constituirán los otros. En este sentido, América se erige identitariamente desde el eurocentrismo, el cual se constituirá en patrón mundial del poder: “[...] los europeos imaginaron también ser no solamente los portadores exclusivos de tal modernidad, sino igualmente sus exclusivos creadores y protagonistas" (Quijano 790), legitimando su dominio en los espacios conquistados. A medida que se va desarrollando la historia, este poder irá adoptando distintas formas: la conquista y el colonialismo; la del patriarcado y su lógica falogocéntrica; y la de la racionalidad instrumental generada por el desarrollo del capitalismo y la tecnociencia.

De esta forma, pensar en cómo las sociedades son escritas mapeando los cuerpos desde la matriz del poder, remite a una voz hablante que asume una postura contestataria para hacer comparecer a las instituciones, al saber, a la historia y, en general, al sistema.

Desde tal perspectiva, me interesa revisar el corpus total que constituye la narrativa de la autora. Su primera novela Más allá de las máscaras (1983) se elabora a través de una voz enfadada que interpela al sistema y a todas 'las señoras'. La voz hablante, representada en el personaje de Cristina, expone las marcas del patriarcado sobre el signo mujer que la 
define desde el sentimentalismo y la cursilería del amor. La autora pone en relieve el poder de la palabra escrita para re-situar a la mujer al introducir un decir otro a través de la exploración del cuerpo y el erotismo de Cristina. Luego, Frutos extraños (1991) marca una nueva etapa en su escritura. El conjunto de cuentos se elabora a través de lo fantástico para mirar al poder en la conquista, en la discriminación racial, en el desengaño en los inmigrantes frente a la utopía de tierras mejores y los efectos sobre sus vidas del dominio blanco, y la cosificación del sujeto por medio de la lógica de la racionalidad técnica. Muñeca Brava (1993), novela que elabora a sus personajes en la resistencia al orden totalitarista de la dictadura en Chile y su lógica positivista. Las noches de Carmen Miranda (2002) pone en el centro del problema las minorías genéricas, siendo la identidad de la artista portuguesa/brasileña Carmen Miranda una categoría de 'lo latino' inventada por el poder de la industria del cine y el espectáculo y que, al mismo tiempo, es centro del problema mujer-nación en su subordinación al orden patriarcal. Las pistas de Lucifer (2014), conjunto de relatos que, a través de una estética de lo fantástico, elabora 'pistas' para dejar ver cómo el mal y la violencia se ejercen desde el poder. Por último, Travesías del hombre lobo (2015) da cuenta de la metamorfosis que sufre el protagonista para convertirse en una 'bestia' que refleja, a su vez, la transformación de Chile en la dictadura de Augusto Pinochet. Además, constituye la metáfora de la ambigüedad entre un 'sujeto de bien', desde la apariencia del orden, hasta un otro que ejerce el mal. En Alegorías de la derrota. Idelber Avelar, refiriéndose a la producción simbólica postdictatorial, señala que esta tiene la marca de lo intempestivo, es decir, "[...] aquella mirada que aspira ver en el presente lo que a ese presente le excede -el suplemento que el presente ha optado por silenciar (18). Así, esta literatura expone lo no resuelto y lo pendiente, abriéndose paso y legitimándose discursivamente.

Si bien existe una vasta producción crítica sobre el trabajo de Lucía Guerra, no existen estudios que tomen como eje transversal las nociones de poder y resistencia en toda su narrativa. Un posible acercamiento se encuentra en "Representaciones de Resistencia en las novelas de Lucía Guerra" (2001) de Silvia Nagy, pero solo examina Más allá de las máscaras, Frutos extraños y Muñeca Brava, teniendo como eje de su estudio: la reescritura subalterna de la historia y las particularidades de la resistencia llevada a cabo por mujeres. 
Como soporte teórico central, los postulados de Foucault son útiles para trabajar poder y resistencia, pues para el pensador francés ambos conceptos están vinculados: "Que donde hay poder hay resistencia, y no obstante (precisamente por esto), ésta nunca está en posición de exterioridad respecto del poder" (Historia de la sexualidad 1 191, paréntesis del original). En consonancia con el autor y con la resistencia que elabora Guerra en su narrativa, la admitimos como un acto de creación y de re-significación para la condición del sujeto.

En definitiva, el presente artículo explora la narrativa de Lucía Guerra admitiendo que es posible pensar que la escritora piensa la 'realidad' de-construyéndola, posibilitando un principio de clasificación y de organización que se ensamblan para crear fisuras en el poder que articulan sus novelas y cuentos, evidenciando gestos de resistencia frente a las subjetividades e ideologemas del orden oligárquico, patriarcal y falogocéntrico ${ }^{1}$.

\section{Las pistas del poder}

La nación ha sido uno de los constructos más importantes en la historia del Occidente moderno. A partir de esta noción se crea un eje transversal que permitiría la constitución y afirmación de las identidades, pues desde esta lógica: "La nación es siempre resultado de un proceso eminentemente político que involucra la selección, más o menos arbitraria, de un conjunto de características culturales que se consideran sus marcas típicas e inconfundibles" (Castro 252) y elementos identitarios y colectivos propios de la concepción de Estado-nación.

Desde tal reconocimiento, interesa exponer las estrategias y prácticas que articulan el poder y elaboran la constitución de la identidad de los sujetos en la narrativa de Lucía Guerra. Es importante considerar como referente la articulación que hace Foucault de saber/poder, es decir, el hecho que desde ciertas estructuras se elaboran 'verdades' que inciden en la práctica de control y disciplinamiento sobre los sujetos, “[...] y cómo estos tipos de discursos pudieron formarse históricamente, y sobre qué realidades históricas se

\footnotetext{
${ }^{1}$ El falogocentrismo como orden simbólico construye esencialismos para definir el mundo desde una lógica masculina a partir de la relación razón/lenguaje. Judith Butler lo define como: “[...] discurso, unívoco y hegemónico masculino que acalla lo femenino como un lugar de multiplicidad subversiva". El género en disputa: El feminismo y la subversión de la identidad, Paidós, Barcelona, 2007, p. 75.
} 
articulan" (Foucault, Estrategias 146). Esta mención interesa en cuanto responde a una genealogía que pone de manifiesto los sistemas de pensamiento en la contingencia de su formación histórica y en sus modos de configuración.

Las categorías subjetividades institucionales y sujeto silenciado me permiten dar cuenta desde dónde Guerra elabora las 'fisuras del poder'. La primera totaliza la forma de ser y estar incidiendo en el silenciamiento que, en el corpus de Guerra, significa entrar a una zona de precariedad del sujeto al no ser y decirse desde sí mismo: “[...] exclusión de aquellos que no tienen derecho al saber, o que no tienen derecho más que a un determinado tipo de saber" (Foucault, Microfísica 32). Tal silencio y limitación en el acceso al saber dialoga con Judith Butler y su análisis sobre los símbolos culturales que se inscriben en toda corporalidad y que lleva a algunos a caer bajo sospecha: "Esta matriz excluyente mediante la cual se forman los sujetos requiere pues la producción simultánea de una esfera de seres abyectos, de aquellos que no son 'sujetos', pero que forman el exterior constitutivo del campo de los sujetos" (19). Si bien las subjetividades institucionales materializan el ser y el estar en el territorio nación, y hay sujetos que se resisten a la representación, existirá algo así como un excedente que los convertirá en desamparados y desconocidos.

En Muñeca Brava el coronel Arreola, a quien el dictador le ha encargado realizar un estudio científico de las prostitutas, encarna la lógica del positivismo. Su modo calculado, medido y calibrado le permite manejar con 'exactitud' las tareas cotidianas de su vida profesional y familiar las que están 'perfectamente trazadas'. Experto en métodos de tortura y fiel al "Gran Benefactor de la República" -el dictador- ha seguido con su característica prolijidad la tarea que se le ha encomendado, y después de leer las fichas de las prostitutas, ordenadas y clasificadas según la ciencia:

[...] opina, con vigorosa convicción, que las mujeres no son más que vientres y vagina, dos fragmentos de cuerpo que las destinan, desde el mismo nacimiento, a ser madres o prostitutas - ambas igualmente atadas a un placer masculino que, en ellas, se transforma en sublime procreación o en pecado deleznable. (Guerra, Muñeca 46)

Su opinión refleja la negación y reducción de la historia particular de las mujeres desde una perspectiva patriarcal naturalizando restricciones tangibles que la dejan 
subordinada bajo esa lógica. Su corporalidad dibujada por el falo, hacen de ella solo un cuerpo para el uso masculino: la restricción a ser madre y esposa, lógica del ideologema de la familia, y con ello concebir a los futuros ciudadanos. Por otro lado, es objeto de uso para el goce que la deja subordinada a la sexualidad masculina, dos funciones que la mantienen en una quietud respecto a sí misma ${ }^{2}$. En el caso del cuerpo prostituido implica la expulsión inmediata de la comunidad nacional, pues es el otro abyecto. Luego se lee:

Durante sus quince años de matrimonio, el coronel Arreola había sabido mantener el lazo conyugal bajo las estrictas leyes de la mesura y la sobriedad. Nunca permitió que su esposa traspasara las fronteras de la decencia en las relaciones sexuales que él dirigía una vez por semana, sábado o miércoles [...] Al año de casados, dos veces ella intentó mover las caderas, pero él, con movimiento presto, la detuvo sujetándola por los muslos mientras urgía el descenso de su propio orgasmo. (Guerra, Muñeca 31)

El pasaje se puede leer desde la maquinación económica y política para el disciplinamiento de los cuerpos. Económica porque la energía erótica está calculada, medida y equilibrada solo para aquello a lo que está pensada la mujer desde el discurso del poder, es decir, la reproducción. Política porque la estructura del poder patriarcal la deja fuera de sí misma y de toda participación autónoma en una relación sexual de dominación sustentada en un principio de división: “[...] ese principio crea, organiza, expresa y dirige el deseo, el deseo masculino como deseo de posesión, como dominación erótica" (Bourdieu, La dominación 35). El cuerpo de la esposa de Arreola como, asimismo, el cuerpo de la mujer en la sociedad patriarcal, es intervenido para hacerlo 'femeninamente' adecuado a partir de las subjetividades institucionales.

De igual modo, en la novela Más allá de las máscaras Lucía Guerra elabora por medio de su subjetividad los códigos patriarcales construidos como grandes relatos:

Ellos, los nuevos genios del mundo, entonces inventaron un núcleo familiar para sustentar su diabólica jerarquía de poder: el padre, la autoridad máxima, dueño y señor de la casa, la madre (señora de)

\footnotetext{
${ }^{2}$ Frente al examen de los postulados de Freud, Guerra expone la condena de la mujer a la pasividad en su posición de objeto: "Ella, es así, el signo viviente de la cabeza decapitada de Medusa, despojo sangrante que, sin embargo, resulta de gran utilidad para reafirmar el poder del falo y sus estructuras patriarcales”. La mujer fragmentada. Historias de un signo, Santiago de Chile: Editorial Cuarto Propio, 2006, p.45.
} 
pariendo hijos que no llevarían su apellido, laborando silenciosamente en la cocina [...] El hombre, amo de todo lo creado, Jehová, Padre, Hijo y Espíritu Santo [...] poseedor de la palabra. $(29$, los paréntesis son del original)

La escritora no solo apunta al discurso patriarcal, sino también a las concepciones falogocéntricas referidas a la supremacía de lo masculino como punto de referencia para construir significados operando en las narrativas mediante esencialismos. Butler define al falogocentrismo como “[...] una economía que produce lo 'femenino' como su exterior constitutivo" (66) y que, a la vez, sitúa a la mujer en lo sagrado-religioso de la institucionalidad y en el ejercicio del poder en la historia. La triada católica masculina extiende su 'verdad' por toda la historia de la sociedad. Lo masculino considerado como viril, se asocia, por lo demás, a la virtud, es decir, el poder de obrar, el poseer la fuerza, y el recto modo de proceder. Dentro de este contexto, la construcción de la masculinidad es uno de los ideologemas que sustenta la invisibilidad de la mujer, la que queda subsumida al interior del hogar resguardando a la familia. Bajo este prisma, leo el mito fundante del rol masculino en el núcleo familiar y en la sociedad como poseedor de la palabra y el saber, que definen su ejercicio del poder en la historia, en especial, en el silenciamiento de la mujer. También tiene que ver con la sociedad disciplinaria que se construye por medio de un saber de vigilancia para la institución del matrimonio que funciona: "[...] como un microscopio de la conducta [...] un aparato de observación, de registro y de encauzamiento de la conducta (Foucault, Vigilar 178). Es así como la preminencia del poder masculino opera desde varias perspectivas. Alberto, esposo de Cristina, le es infiel, licencia propia de las sociedades patriarcales, pero cuando se entera de la infidelidad de su esposa no es posible la concesión: "Me las vas a pagar, puta de mierda" (Guerra, Más allá 57). Cristina es 'puta' por la constitución histórica del signo mujer que radica en la conducta y saber masculino que funciona como 'verdad', construyendo categorías inamovibles para los roles al interior de la familia.

Por otro lado, dentro de los espacios de enunciación que elabora Guerra, y en el plano de lo deontológico y racional, emerge el poder mediante el ejercicio de la violencia que interrumpe la noción de lo humano dejándolo en entredicho. Es la tensión que vive el asesino serial de Travesías del Hombre Lobo, Antonio, un sujeto de doble faz, estudiante de literatura y perteneciente a una familia tradicional, intenta comprender por qué es atraído 
por una prostituta perteneciente a la clase baja. Se enoja consigo mismo porque la desea como un 'lobo hambriento'. Quiere olerla, saborearla y piensa constantemente: “[...] en sus senos, en el olor de sus axilas y el sabor espeso de su vulva” (Guerra, Travesías 115). Pareciera ser que solo las 'fuerzas del mal' podrían confundir a quien ha trazado su camino por medio de las ciencias. De ahí que Antonio se desplaza por su conciencia desde una concepción subjetiva de su crimen que ha quedado impune. Su 'errático' actuar pareciera radicar en lo oscuro y maligno que caracteriza a las mujeres: "Verónica y todas las otras mujeres me parecieron unas satánicas impostoras que, tras sus sonrisas zalameras, se dedicaban a revolver los calderos de la herejía" (Guerra, Travesías 114, énfasis del original). En su voz misógina se reflejan siglos de oscuridad en torno a la mujer configurada desde lo siniestro. Se puede observar una relación propia del estado de vacilación entre lo racional y lo irracional que constituye lo fantástico. La estrategia de la escritora para trabajar la doble faz en la metamorfosis de Antonio cruza crimen-oscuridad, misterio-mujer: el asesino serial no se puede explicar por qué es atraído por Verónica y el mundo del prostíbulo que lo seducen, pero, a la vez, le repugnan. Por otra parte, la metamorfosis que sucede por la luna, elemento femenino, es la única posibilidad para comprender por qué se convierte en abyecto; hombre lobo que devora, finalmente, la vida de Verónica. Pareciera subrayar la dicotomía Naturaleza/Mujer, Cultura/Hombre.

La violencia masculina amparada por el culto a la virilidad, tan propio de la sociedad patriarcal, la encontramos en la figura del 'macho' en el cuento 'Emboscadas de la memoria":

\footnotetext{
'Allá en la celda trece está la huevona que no ha querido hablar con ningún tratamiento de tortura, échensela entre los cuatro pa' que aprenda a cooperar'...Yo al principio no entendí bien lo que quería decir hasta que, al llegar a la celda, Ramírez se bajó el cierre del pantalón... Arrinconada en la oscuridad estaba ella, como un animal asustado, y cuando Vélez prendió la luz vimos que tenía la cara toda moreteada... ‘ ¡Al abordaje muchachos!' (Guerra, Las pistas 50)
}

"Emboscadas de la memoria" narra desde la perspectiva de Pancho, soldado de uno de los campos de detención de la dictadura de Pinochet, su participación en la tortura y violación de una de las detenidas. La presión de los otros soldados tensiona su 
masculinidad al gritarle que 'no funciona con las mujeres' o que es un 'maricón' y gatilla su 'valentía' para, finalmente, matarla: “ßBravo, huevón! Te pasaste” (Guerra, Las pistas 52), celebra el soldado Ramírez la 'hombría' de Pancho. Tal desborde, muestra la asimetría entre géneros: "En el abuso de poder uno desborda lo que es el ejercicio legítimo de su poder e impone a los otros su fantasía, sus apetitos, sus deseos" (Foucault, La Hermenéutica 118). Es el poder transformado en violencia, ejercicio siniestro de los torturadores.

Esta violencia que proviene de un poder institucional y estructural es ancestral. En el cuento "De brujas y de mártires", Don Pedro de Alvarado llega a Guatemala por orden del rey a conquistar tierra americana. Pero también lo hace del cuerpo y del sentido de pertenencia de la "india" Niniloj:

En la masa inerte de sus nalgas, ella siente los golpes de esos otros muslos que la acometen con furia de espadas y arcabuces. Indefensa vuelve la cabeza y divisa los ojos lujuriosos del enemigo, de ese hombre cubierto de sudor que se empeñó en invadir su patria y ahora se empecina en poseer su cuerpo. (Guerra, Frutos 47)

Niniloj yace estupefacta en medio de las armas del conquistador, símbolo de los objetivos imperiales de dominio y sometimiento que ejerció la fuerza y la violencia en los habitantes de las tierras americanas. La india es desgarrada de su cosmovisión por la fuerza productiva del poder que ha instalado en el conquistador su derecho a hacer posesión de ella. En silencio, Niniloj padece el poderío del español. Es la relación entre el dominador y el dominado lo que converge con el planteamiento de Foucault:

[...] en el comportamiento sexual hay un papel que es intrínsecamente honorable y al que se valora con derecho pleno: es el que consiste en ser activo, en dominar, en penetrar y en ejercer así su superioridad [...] Los esclavos, ni qué decir tiene, están a disposición del amo: su condición hace de ellos objetos sexuales. (Historia de la sexualidad II 234)

Ese derecho al que refiere Foucault tiene su sustento en la convicción de que los indígenas y todo sujeto fronterizo portan lo abyecto. Las 'verdades' instituidas en el pensamiento de Don Pedro de Alvarado están por encima de la moral, las virtudes y los 
sentimientos que permitirían anular su goce. No puede entender a ese otro: "Vamos, mueve el culo, dale. Trabaja, india del diablo, muévete te digo" (Guerra, Frutos 53). De esta forma, Niniloj está sometida por el falo. En efecto, desde su poderío masculino ella le pertenece; él es un conquistador que toma posesión del territorio y de todo lo que hay en el mismo.

En el cuento "Secreto de familia", Guerra va a los lugares de la memoria para seguir explorando el poder, focalizando su interés en la exposición de la ruta histórica de la violencia a través del incesto: "Nunca sabía cuándo el acoso volvería a repetirse. Desde aquel día en que estaba enseñándole a nadar y ella aún no entraba a la escuela primaria" (Guerra, Las pistas 76). El cuerpo de Alicia es abusado sexual y emocionalmente por su tío Antonio desde que era niña. Aquel que fuese su primer amor es ahora, en su edad adulta, quien malogró su sensualidad y su derecho al placer. El cuerpo porta significado, sus comportamientos deben ser acordes con la estructura del poder de las sociedades disciplinarias, por eso Alicia también siente culpa por su placer guardado secretamente en la memoria que fue despertado en el abuso. Quiere gritarlo; desenmascarar al tío violador frente a toda la familia reunida por el cumpleaños de la abuela, matriarca y guardiana del orden, pero su historia femenina teñida de violencia y padecida en la mutilación de su palabra y de su cuerpo, no le resulta suficiente para romper el mito de la 'sagrada familia'. Entonces, calla.

\section{Fisuras en el poder}

El entramado de las historias de las novelas y cuentos de Lucía Guerra se articula en distintos espacios y temporalidades, tanto en el tránsito de los personajes desde sus vidas privadas al espacio público, como viceversa. De ahí que el sujeto de subjetivación sea, por una parte, quien está al interior de la nación, pero en tensión frente a los lineamientos que establece al visibilizar otra dimensión de su identidad y, por otra, aquellos que se encuentran en situación de marginados, pero desplazándose por los intersticios del poder: la 
mujer, la inmigrante, la prostituta y el homosexual, constituyéndose en voces subalternas y produciendo agenciamiento ${ }^{3}$, deshabituándose de este modo del entramado del poder.

Las marcas escritas sobre los cuerpos y las identidades mediante un proceso de diferenciación de los sujetos son confrontadas por medio de estrategias que Lucía Guerra elabora en sus personajes para resistirse a la sujeción del poder. Desde tal perspectiva, propongo la categoría cartografía del poder, entendiendo a la cartografía como una propiedad del acto rizomático, el cual “[...] está totalmente orientado hacia una experimentación que actúa sobre lo real” (Deleuze y Guattari 17), para dar cuenta en el análisis de su obra cómo Guerra fisura el poder colándose por los códigos institucionales, culturales, políticos y textuales haciendo, de este modo, resistencia.

El inicio de Más allá de las máscaras es emblemático desde esta perspectiva: "La verdad, señora, es que no sé cómo empezó todo esto. Mi historia no tiene nada que ver con esas otras historias escritas por los hombres, ni las de alcoba, ni las de fusiles, ni las de laberinto en una biblioteca" (10). Guerra se orienta a un nuevo territorio a través de la voz de Cristina y su proceso de desenmascaramiento que no es otra cosa que deshacerse del yo producido como efecto de las relaciones de poder. En un gesto de resistencia tensiona al orden oligárquico, patriarcal y moralista a través de la transgresión de los formatos dominantes propios de los signos falogocéntricos: la alcoba para el discurso de la sexualidad que configura el signo mujer; los fusiles para quienes han detentado el poder sobre la vida y la muerte; y la biblioteca para desnaturalizar la idea que la razón, la ciencia y el saber lo portan los hombres. Guerra da un salto por las figuras básicas de la cultura del Occidente moderno, desestabilizando el orden normalizador, tal como se advierte en el próximo pasaje:

De pronto sentí que mi vida había adquirido sentido. Haría saltar las bellas cerraduras para abrir los cuartos secretos de la verdadera femineidad destapando pozos de furia, rompiendo máscaras, rasgando finos encajes, astillando cristales para mostrar, en su

\footnotetext{
3 Deleuze y Guattari definen el agenciamiento como "[...] líneas de fuga, movimientos de desterritorialización y de desestratificación. Las velocidades comparadas de flujo según esas líneas generan fenómenos de retraso relativo, de viscosidad, o, al contario, de precipitación y de ruptura. Todo eso, las líneas y las velocidades mesurables, constituye un agenciamiento (agencement)". Mil mesetas. Capitalismo y Esquizofrenia. Valencia: Pre-Textos, 2004, págs. 9-10.
} 
desnudez, aquel alambre carcomido que nos fijaba en una galaxia llena de fraudes. (Guerra, Más allá 117)

A través de Cristina, que comienza a vivir su propia historia al deshacerse del artificio señora/esposa, Guerra plantea nuevas alternativas desmitificando concepciones hegemónicas representadas en: los secretos 'femeninos'; las emociones contenidas; las máscaras del ideologema matrimonio y el 'fraude' de amarse 'hasta que la muerte los separe'. "Astillando cristales" es la fisura que Guerra visualiza en las relaciones de poder a partir de las que se configura el signo mujer. Usa un artefacto, el espejo, como una forma directa de hacer ver en quienes podríamos transformamos en el devenir. Finalmente, Cristina deviene en sí misma desdibujando las barreras que limitan la re-significación de la identidad adscrita.

En Muñeca Brava, Alda, la "flor de pecado", no solo es la prostituta que logra resistir al interrogatorio que le realiza el coronel Arreola, sino que, además, se transforma en la figura de la resistencia en la dictadura que lleva a cabo el "Gran Benefactor de la República":

[...] le decía que me llaman mujer mala, también me dicen mujer pública [...] Yo entiendo que por esto quieren decir que pertenece a muchos hombres o a todos los hombres, como las plazas o los focos [...] en contraste con la mujer privada, fijese. Aunque, para serle franca y aquí le estoy dando una opinión muy personal que espero no tome a mal, mi general, yo creo que no hay mucha diferencia. Después de todo, a ellas el marido las alimenta, les da techo y abrigo por la misma cuestión no más, con la única diferencia de que ellas tienen que cocinar y lavar la ropa sucia mientras que a nosotras nos pasan el billete y se van. (Guerra, Muñeca 41)

El mapeo del poder que realiza Guerra encuentra nuevos puntos y líneas. Lo imprevisto pasa por otorgarle a la prostituta voz política. El cuerpo, que era puro objeto, posee una ideología sobre su condición social en relación a las que viven al interior cobijadas en el matrimonio, transformándolas en las otras. La voz irónica y subversiva de Alda ante un Arreola que escucha en silencio escudriñando en esa mujer misteriosa, parodia a quien controla desde el poder. El torturador es des-armado nada menos que por una 'puta' que fisura la comunidad nacional al hacer una línea de fuga en su condición de 'inferior' y 
situarse horizontalmente frente a la mujer casada. En este gesto, la escritora le otorga a la mujer/prostituta una conciencia política sobre su propia historia. La resistencia se despliega, también, en el emplazamiento que realiza Alda al saber racional que detenta el coronel. Por otra parte, el desenfado con el que se dirige a él es relevante, pues lo hace en un campo de concentración en el que se encontraban aquellos que eran considerados peligrosos. Alda está siendo examinada desde la lógica de las sociedades disciplinarias, donde el ejercicio del poder es un placer sobre sexualidades prohibidas: "Placer de ejercer un poder que pregunta, vigila, acecha, espía, excava, palpa" (Foucault, Historia de la sexualidad 147), que es la tecnología que usa Arreola y de la cual se burla Guerra.

En otro pasaje, Doña Carolina, quien administra el prostíbulo, dirige el velorio de la fallecida Meche, la prostituta de ancestro mapuche, elevando una plegaria que es una fisura relevante a los ritos de la institución católica:

Bendito fue tu cuerpo cuando, en tus años de juventud, diste a los hombres gozoso albergue entre tus piernas. Experta entre las expertas de nuestro santo oficio, a cada hombre que se allegó a tu lecho, lo supiste encaminar por los múltiples senderos del placer y, cuando salió de tu cuarto, nunca pagó de mala gana porque el vaivén de tus caderas no tenía precio sobre esta tierra. (Guerra, Muñeca 163)

Las palabras de Guerra son beligerantes frente a lo que se plantea como lo otro para las instituciones y sus códigos morales. En entrevista realizada por Joseph Chrzanowski, la escritora se refiere a su escritura: “[...] yo diría que es el estilo de una mujer latinoamericana consciente de los traumas, consciente de las nuevas conceptualizaciones acerca de la mujer" (330). La imagen del ritual que exalta el cuerpo, el placer y las artes del erotismo de la 'mujer pública', representa lo declarado por Guerra y se constituye en posibilidad para la resistencia, fundamentalmente, al convertir a la prostituta en 'guardiana del placer' y poseedora de la palabra. Las voces marginales se elevan a las alturas en un más allá para otorgarle la concesión de la trascendencia, parodiando el ritual cristiano al darle un lugar a la prostituta quien es digna de ser consagrada a un culto. La introducción de Meche, prostituta de ancestro mapuche, en la historia de la novela, es otro gesto de resistencia. Esta subcultura negada políticamente desde de la cultura oficial se abre un espacio en la escritura legitimando su existencia. En La ciudad ajena: Subjetividades de 
origen mapuche en el espacio urbano Guerra afirma": "Para una nación en la cual la civilización es sinónimo de cultura europea, dentro de un proyecto que exalta la raza blanca, el espacio urbano y las disquisiciones del Espíritu el Intelecto, el bárbaro mapuche representa el contratexto del ciudadano ideal" (62). Así, establece nuevas relaciones para ingresar a los espacios silenciados de la historia

Desde este mismo nivel de análisis, la muerte de la 'muñeca brava', Alda, es un pasaje interesante de mirar como salto de su lugar fronterizo a uno de resistencia:

Con una venda en los ojos y las manos atadas, Alda, desafiante, eleva el busto [...] ha dejado de ser un juguete de pasión y su bravura de muñeca brava pertenece ahora a regiones muy diferentes. Haciendo un leve movimiento con la cabeza, desecha la imagen de la mujer que campanea de norte a sur ofreciendo su cuerpo para el acto intranscendente de un encuentro sexual. Ella ya no es más la flor del pecado que se marchita muy pronto en la memoria. (Guerra, Muñeca 169)

Alda es la sujeto ${ }^{5}$ resistente que ocupa el mismo lugar que cualquier héroe de la nación al cruzar el umbral de cuerpo mercantilizado a cuerpo político. Con un gesto propio de la mujer contemporánea en la lucha por la reivindicación de los derechos, Alda, Meche y Martina fundan la comunidad del sentir. La escritora las vincula por medio de lazos fraternos sustentados en la lealtad no solo para combatir al dictador sino, además, para dignificar sus vidas. Este gesto es de gran importancia, pues la mujer 'pública' estaba al margen de la historia. Guerra las incluye en el campo social y en el campo político rebasando el límite de lo permitido. Este hecho tendrá una gran consecuencia, pues la 'flor de pecado' tendrá una muerte propia de los que caen en manos del dictador.

Por otro lado, la negación de un espacio legítimo a la homosexualidad, es elaborada en "Ocasos" del libro de cuentos Frutos extraños. En el homenaje póstumo que realiza el amigo/pareja de John mientras se prepara para acudir a su funeral, la voz hablante afirma:

\footnotetext{
${ }^{4}$ Cabe destacar que Guerra estudia en La ciudad ajena: subjetividades de origen mapuche en el espacio urbano nuevas articulaciones de la identidad para la legitimación de la cultura mapuche a través de la resistencia.

${ }^{5}$ Con la feminización del sujeto, quiero subrayar que Alda se constituye simbólicamente en la resistencia frente a las brechas que han limitado a la mujer como sujeto histórico en una doble dimensión: de mujer a sujeto histórico, de 'puta' a sujeto político.
} 
Dios había decidido arrojar un muro definitivo sobre tu existencia [...] Aquel te enviaba, como en los tiempos de Sodoma y Gomorra, la destrucción de tu cuerpo por amar con 'el mal amor' con nuestro amor que no conduce a la procreación $[\ldots]$ por regocijarte $[\ldots]$ sino en el tórax musculoso de un joven que como tú no desea sumirse en el misterio vaginal. (Guerra, Frutos 179-0)

Bajo esta lógica aparece la dominación simbólica que sufren los homosexuales afectados por categorizaciones y estigmas más radicales que 'lo femenino'. Es “mal amor" el de John porque hasta los sentimientos deben estar encauzados en rutas trazadas, predeterminadas y cristalizadas en la conciencia de los 'buenos ciudadanos' por sobre una diversidad que es clausurada. La vagina es un misterio porque es un lugar desconocido, enigma que no interesa descifrar. Guerra lleva la realidad al texto no para representarla como un calco (Deleuze y Guattari) sino para problematizar la experiencia. Es así que crea un lugar para un sujeto cuya constitución aún está pendiente por los efectos del poder hegemónico que describe Bourdieu: “[...] se impone a través de los actos colectivos de categorización que hacen que existan unas diferencias significativas, negativamente marcadas, y a partir de ahí unos grupos, unas categorías sociales estigmatizadas" ( $L a$ dominación 143-4). En el mismo tono de las marcaciones de Bourdieu a las que se refiere el pensador francés, se lee en otro pasaje de "Ocasos":

Esa noche comprendí de verdad que tu elección de amar a tu manera era también un acto de desafío frente a este mundo que rehusaba cobijarte. Amaste, John, con el oído atento a los impulsos de tu cuerpo y de tu ser que eran lo mismo, eliminando, con el golpe grande y armonioso de tu libertad, todas las regulaciones de una moral que a mí me había hecho vivir mi propio cuerpo y mi propio ser como el desván vergonzoso de traumas y pecados (Guerra 178-9).

La postura de la escritora chilena es política frente a los dispositivos de poder que atraviesan los cuerpos. Es un gesto restaurador, ante el placer genuino de un cuerpo muerto legitimado por encima de un orden social que le privó de la libertad social. En esta dirección, Guerra afirma en Ciudad, género e imaginarios urbanos en la narrativa latinoamericana que: "El cuerpo homosexual deviene, entonces en lo 'no apropiado' e 'indeseable' ideologema que, como en una espiral, se extiende a todos los ámbitos socio- 
culturales" (199). El deseo fragmentado, anulado y absorbido por los discursos dominantes, se sitúa en un espacio marginal, precisamente porque ese cuerpo e identidad del homosexual, interrumpe el orden. Gilles Deleuze establece, a su vez, que: "El poder es al mismo tiempo masificador e individualizador, es decir que constituye en cuerpo a aquellos sobre los que se ejerce, y moldea la individualidad de cada miembro del cuerpo" (4).

En Las noches de Carmen Miranda, Lucía Guerra elabora la negación de lo identitario desde un contexto ideológico y político de la inmigrante latina en tierra norteamericana: "Hollywood me ha transformado en un carnaval sin sentido, en ese tipo de ‘jubilee' o exaltación hueca de la alegría que tanto practican en este país y que nada tiene que ver con la felicidad verdadera" (177). Carmen Miranda toma conciencia de la artificialidad de su cuerpo, forzada por la industria del espectáculo, y de su identidad disciplinada y cosificada:

Carmen se puso a cantar, como si en un vómito hubiera exorcizado todo ese malestar hacia las limitaciones que le habían impuesto a su carrera y que ella cargaba, en silencio [...] Ella adrede exageraba la pronunciación para darle una inflexión aún más sensual y cuando al concluir la canción alargó los labios en un beso y onduló el cuerpo agachándose hasta el suelo, sintió que le encantaba transgredir la imagen que la había aprisionado porque hacer una parodia de sí misma requería también arte e imaginación [...] sintió que toda la máquina infernal de Hollywood y el negocio de la entretención había degradado su arte. (Guerra, Las noches 208)

El pasaje es una forma de subversión frente a la subjetivación que se hace de la artista al elaborarla artificialmente como un ícono latino. Así, por medio del quiebre que hace la artista de su imagen adscrita, Guerra resiste a todo intento totalizante que, para este caso, remite a un poder/saber sobre una identidad que no interesa descubrir y que, por el contrario, se invisibiliza en el escenario de un contexto hegemónico.

Otro gesto de Guerra, en su crítica hacia los discursos y representaciones convencionales, se encuentra en Más allá de las máscaras: "Otro día cualquiera, dejas correr el agua de la tina [...] contemplas tus muslos, tu vientre un poco abultado y dejas deslizarse tu mirada hasta el pubis. Con estupor descubres entonces una cana en el enmarañado vello oscuro" (Guerra 13). La escritora transgrede la convención de no representar el envejecimiento del cuerpo de la mujer, pues ya no es objeto de deseo desde la 
objetivación masculina: “[...] representarse a sí misma significa transgredir las sólidas construcciones culturales para incursionar en lo no representado y lo no legítimamente representable, en una escritura que implica bucear en las zonas silenciadas de ese Yo" (Guerra, Mujer y escritura 32). La resistencia se realiza para problematizar las representaciones reduccionistas acerca de la mujer preservadas por las estrategias de poder. Lucía Guerra tuerce ese destino al incorporar en su escritura la dimensión afectiva y corporal de la mujer.

En "Un encuentro en los márgenes" y "Curriculum vitae" de Frutos extraños, se muestra la resistencia como acto creativo en la escritura de mujeres. En el primer relato, Guerra trae desde otro espacio, otro tiempo, la figura de la escritora argentina decimonónica Juana Manuela Gorriti. La descubre: “Aprisionada entre cientos de volúmenes escritos por los intelectuales verbosos de tu país" (Guerra, Frutos 185) como una compañera en resistencia frente a una academia dominada por los hombres que, como portadoras de género, debieron superar los límites de su clase. Se trata, además, de la posible censura ejercida por la estructura del campo de dominación simbólico que determina la forma, y que la escritora expone como problema en su narrativa, pues tal como señala Bourdieu:

La censura nunca es tan perfecta y evidente como cuando cada agente sólo dice lo que está objetivamente autorizado para decir: ni siquiera tiene que ser su propio censor puesto que, en cierto modo y para siempre, está censurado a través de formas de percepción y expresión que ha interiorizado y que conforman todas sus expresiones (¿Qué significa hablar? 140-1).

Por otra parte, también es posible leer la inmediatez y lo estrictamente utilitario que tiene la escritura cuando se transforma en empresa que limita el ejercicio del pensar desde la autonomía. En un acto autorreflexivo, la narradora se pregunta: “¿Es la escritura para nosotras el sinónimo de un vómito subversivo y no lo que los hombres vanidosamente llaman un oficio?" (Guerra, Frutos 186). Como creadora, la autora pone de manifiesto cómo la escritura de mujeres tensiona la lógica masculina que construye un rol ideológico crucial en la determinación de lo que son y hacen las mujeres que escriben. 
Luego, prosigue su diálogo: "Tú y yo sabemos que, en el injusto tejido de la Historia, tu rescate y el mío han logrado suplantar la dulce cabellera de Rapuncel por un trenzado que derribará, con golpes de péndulo, a los príncipes que impunemente se robaron todas las victorias" (Guerra, Frutos 189). El pasaje es una especie de anhelo de memoria crítica. Una llamada al consenso fraterno para saltar en comunión por encima de los prejuicios, desmitificando los ideologemas que señalan que la mujer solo esperará a un príncipe azul que la salvará del encierro, para este caso, literario.

Asimismo, en "Curriculum Vitae" Guerra busca en su propia escritura y en la recepción que se ha hecho de ella, los signos de las prácticas del poder, haciendo del acto de decirse a sí misma un acto de resistencia frente al canon: "EN LÍNEAS HORIZONTALES toda mi vida pública y publicable, toda ya publicada o por publicarse, se extiende sobre el espacio simétrico de dieciocho páginas" (Guerra, Frutos 191). La escritora tensiona el reduccionismo que la empresa literaria hace de su vida para reclamar aquella versión que no pueden apresar; la propia historia plural y dispersa de sí misma que no debe reducirse a un recetario prescriptivo de la 'buena escritura' que, al fin y al cabo, es donde se juega el verdadero resultado de su obra. Al respecto, resultan iluminadoras las palabras de Jean-François Lyotard en La condición postmoderna (1987):

[...] la ciencia postmoderna hace la teoría de su propia evolución como discontinua, catastrófica, no rectificable [...] no ha habido verdad objetiva alguna - la científica social e, incluso en ciencias naturales - puesto que el saber científico no puede saber lo que es el verdadero saber sin recurrir al otro saber, al relato, que para él es el no saber, a falta del cual está obligado a presuponer por sí mismo y cae así en lo que condena. (25)

De acuerdo a Lyotard, se hace necesario atender a la transformación radical que ha sufrido el conocimiento en la época de la técnica, cuya esencia es la empresa. Hacer el inventario reconociendo las metáforas del dominio totalizante de la razón e interpelar a esos discursos, es fundamental para el rescate de la propia identidad:

En el flujo horizontal de este cauce que ellos llaman mi vida, faltan las defunciones de los vivos, tanto andamio de amor desmoronado, tanto borrón que debió reescribirse con la tinta del desengaño. Tampoco están las muertes de aquellos cuerpos que desaparecieron 
en los canales de cemento de alguna ciudad ya nunca más vista. (Guerra, Frutos 192)

¿Puede escribirse la vida como que si fuera una linealidad constituida por datos y hechos que proporcionan orden para hacerla inteligible? Obviamente que no. La vida es producto del dinamismo y el des-orden de la propia experiencia imposible de apresar en su totalidad por una ruta trazada desde cierta lógica. De este modo, la academia caracterizada por un fuerte énfasis en la productividad como dispositivo de regulación del conocimiento, termina 'fabricando' identidades. En este sentido, es posible advertir el peligro que la especialización académica desacredite otros saberes ante el conocimiento que hoy se prioriza.

\section{A modo de conclusión}

Examinar la narrativa de Lucía Guerra Cunningham es encontrarse con un proyecto escritural innovador y de gran envergadura para el campo de los estudios literarios hispanoamericanos. La lectura atenta de su narrativa desde el eje poder/resistencia, permite, primeramente, observar cómo la autora explora los silencios del signo mujer y las construcciones históricas, políticas y culturales de lo femenino desde el discurso del patriarcado desarticulándolo en su narrativa y, de este modo, contribuir a la escritura de mujeres al incorporarla como sujeto histórico. El modo de desmontar el engranaje de lectura y escritura sobre y por encima de la mujer interpela a la academia y problematiza su esencia actual: la racionalidad instrumental. En segundo lugar, los recorridos que la escritora realiza por los intersticios del poder articulan un espacio otro de voces subalternas. Su voz es enfática en cuestionar a la historia hegemónica modulando en su escritura a un sujeto que cuestiona y rompe las configuraciones unívocas.

La resistencia coexiste simultáneamente al embate de los tiempos por donde fluye el poder convirtiéndose en un proyecto y/o propuesta de escritura subjetiva y retórica que porta la fuerza suficiente para contribuir en el debate político, cultural y social contemporáneo. Es así que, en su narrativa, la resistencia parte desde abajo: desde el signo mujer, desde las prostitutas, desde los inmigrantes y homosexuales, los que son modulados 
por la escritora con el propósito de deshacer el orden impuesto dando cuenta de su anhelo de cuerpo político.

Ahora bien, si se piensa en la escritura de Guerra como praxis, en tanto representa una reflexión profunda en relación a su tiempo y las problemáticas de los asuntos humanos, el fin primordial es ensayar respuestas que permitan la participación genuina de los sujetos en su historia y en la posibilidad de decirse a sí mismos. La narrativa de Guerra está comprometida con la pertenencia, ahí está parte de su lucha, pues su escritura no es solo de un extrañamiento frente a una historia de desarraigos del sujeto, sino, también, de crear un proyecto que vislumbre al sujeto más allá de todo lo adscrito, de modo de re-pensar nuestro tiempo.

La disyuntiva tiene que ver con estar dispuestos a mantener el discurso y no optar por el silencio ante la imposición de la formalización, pues el campo cultural está condicionado por el sistema de relaciones que establecen los distintos agentes vinculados con el sistema de producción de las obras y su posibilidad de expansión. Guerra da énfasis al discurso comprometido. La palabra viva es la posibilidad de todo sujeto. Se da, entonces, un problema crucial para la teoría literaria: construir estrategias de resistencia en el ámbito de la perspectiva crítica de la cultura. De este modo, se está dando importancia al carácter social de la palabra, se establece su relación con la ideología y se considera a la literatura como espacio social en el que se produce su enunciación.

En efecto, uno de los dilemas contemporáneos más importante de nuestras sociedades es la prevalencia del sistema sobre los sujetos para asegurar su funcionalidad manifestada en; una racionalidad instrumental que reclama la organización planificada de un proyecto de mundo asegurado y anticipado en términos de maquinación; y el modo en que se presenta el conocimiento, cuya velocidad de movimiento no alcanzan a capturar los sujetos que habitan un mundo marcado por la transitoriedad. Es también la sociedad del consumo y del espectáculo que hace del espacio/territorio un lugar más de conformación que de desarrollo de la subjetividad. De ahí que sea relevante abordar las tensiones entre cuerpo y discurso a partir de una literatura que nos conecte con una subjetividad siempre en conflicto, para examinar las posibilidades de un devenir en sujeto histórico que participe en la transformación cultural y política. 
Es así que la propuesta escritural de Lucía Guerra permite unir el campo de la literatura con el de la reflexión política y establecer la relación entre la experiencia subjetiva y lo literario. De este modo, se redefine la literatura eliminando sistemas de referencia y modelos ideológicos totalizadores para instalar otras perspectivas: los modos de vida de los otros, las experiencias de la vida social y cotidiana, la mirada desde abajo y la dignificación de las minorías. Desde ese espacio, Lucía Guerra Cunningham sigue resistiendo y conmoviendo.

\section{REFERENCIAS}

Avelar, Idelber. Alegorías de la derrota: la ficción posdictatorial y el trabajo del duelo. Escuela de Filosofía: ARCIS, 1999. Web. [19/05/2020]. $<$ https://es.slideshare.net/solearteliteratura/alegorias-deladerrota-avelar>

Bourdieu, Pierre. La dominación masculina. Trad. Joaquín Jordá. Barcelona: EDITORIAL ANAGRAMA, S.A., 2000.

Bourdieu, Pierre. ¿Qué significa hablar? Economía de los intercambios lingüisticos. Trad. Esperanza Martínez Pérez. Argentina: Ediciones Akal, S.A, 2008.

Butler, Judith. El género en disputa: El feminismo y la subversión de la identidad. Barcelona: Paidós, 2007.

Butler, Judith. Cuerpos que importan: sobre los límites materiales y discursivos del "sexo". Trad. Alcira Bixio. Buenos Aires: Paidós, 2010.

Castro, Sérgio. "Perspectivas y políticas sobre racismo y afrodescendencia en América Latina y el Caribe". Hopenhayn, Martín y Sojo, Ana. Sentido de pertenencia en sociedades fragmentadas: América Latina desde una perspectiva global. Buenos Aires: Siglo Veintiuno Editores, 2011.

Chrzanowski, Joseph. "Abrir brechas, destapar silencios". Entrevista a Lucía Guerra”. En Anales de Literatura Hispanoamericana 25 (1996): 325- 333. Web. [24/07/2017] https://revistas.ucm.es/index.php/ALHI/article/view/ALHI9696110325A

Chul Han-Byung. Psicopolítica. Trad. Alfredo Bergés. Barcelona: Herder Editorial S.L., 2014.

Deleuze, Gilles. "Postdata sobre las sociedades de control" en Ferrer, Christian. Lenguaje Libertario 2: Filosofía de la protesta humana. Montevideo: Editorial NordanComunidad, 1991.

Deleuze, Gilles y Guattari, Félix. Mil mesetas: Capitalismo y Esquizofrenia. Trad. José Vásquez Pérez. Valencia: Pre-Textos, 2004.

Foucault, Michel. Estrategias de poder. Obras esenciales. Vol. II. Trad. Julia Varela y Fernando Álvarez Uría. Barcelona: Paidós, 1999.

Foucault, Michel. Historia de la sexualidad 1: La voluntad de saber. Trad. Ulises Giñazú. Buenos Aires: Siglo Veintiuno Editores, 2018.

Foucault, Michel. Historia de la sexualidad 2: El uso de los placeres. Trad. Soler Martí. Buenos Aires: Siglo Veintiuno Editores, 2011.

Foucault, Michel. La gran extranjera: Para pensar la literatura. Trad. Horacio Pons. Buenos Aires: Siglo Veintiuno Editores, 2015. 
Foucault, Michel. La Hermenéutica del sujeto. Trad. Fernando Álvarez-Uría Buenos Aires: Fondo de Cultura Económica, 2001.

Foucault, Michel. Microfisica del poder. Trad. Horacio Pons. Madrid: La piqueta, 1992.

Foucault, Michel. Vigilar y Castigar. Trad. Aurelio Garzón del Camino. Madrid: Siglo XXI Editores, S.A., 2000.

Guerra, Lucia. Ciudad, género e imaginarios urbanos en la narrativa latinoamericana. Santiago de Chile: Editorial Cuarto Propio, 2014.

Guerra, Lucia. La ciudad ajena: Subjetividades de origen mapuche en el espacio urbano. Santiago de Chile: Ceibo Ediciones, 2014.

Guerra, Lucia. Frutos extraños. Santiago de Chile: Editorial Cuarto Propio, 1997.

Guerra, Lucia. Las pistas de Lucifer. Santiago de Chile: Ceibo Ediciones, 2014.

Guerra, Lucia. Las noches de Carmen Miranda. Santiago de Chile: Editorial Sudamericana, 2002.

Guerra, Lucia. Mujer y escritura. Fundamentos teóricos de la crítica feminista. Santiago de Chile: Editorial Cuarto Propio, 2008.

Guerra, Lucia. Muñeca Brava. Santiago de Chile: Ceibo Ediciones, 2015.

Guerra, Lucia. Más allá de las máscaras. Santiago de Chile: Editorial Cuarto Propio, 1998.

Guerra, Lucia. Travesías del hombre lobo. Santiago de Chile: Editorial Zig- Zag, S.A, 2015.

Lyotard, Jean-François. La condición postmoderna. 1987. Trad. Mariano Antolín Rato. Buenos Aires: Editorial R.E.I. S.A., 1991.

Quijano, Aníbal. "Colonialidad del poder, eurocentrismo y América Latina". Cuestiones y horizontes: de la dependencia histórico-estructural a la colonialidad/descolonialidad del poder. Buenos Aires: CLACSO, 2014. Web. [15/05/2020]. http://biblioteca.clacso.edu.ar/clacso/se/20140507042402/eje3-8.pdf 